دراسة عن التغيرات الكيمائية والتلوث الميكروبيولوجى في للحوم المطبوخة والمعروضة في بعض المطاعم المحلية في محافظة البصرة

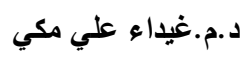

العرق/ جامعة البصرة / كلية الزراعة / قسم الانتاج الحيواني

هدفت الدراسة الحالية الى دراسة التلوث التزنخي والميكروبيولوجى في اللحوم المطبوخة في بعض مطاعم محافظة البصرة لاربع مناطق

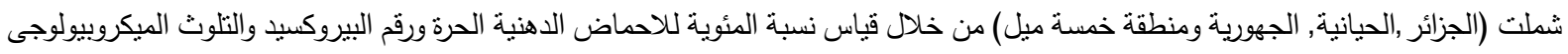

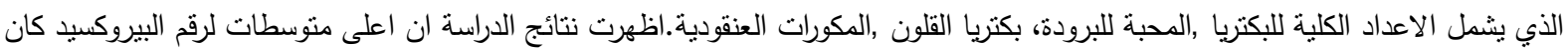

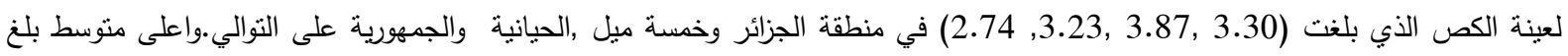

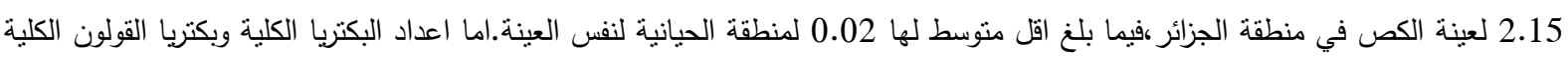

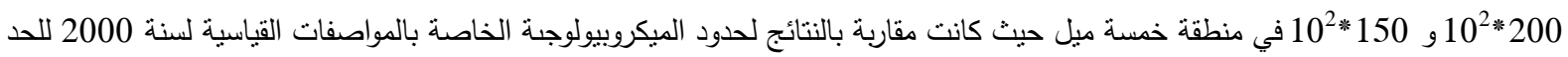

المقرر لها.

الكلمات المفتاحية: التلوث الميكروبيولوجى -اللحوم الحمراء - التزنخ الناكسي - رقم البيروكسيد

المقدمة

تعتبر اللحوم من أهم مصادر البروتينات الحيوانية التي يحتاجها الانسان لامداد خلايا جسم الانسان وتتميز اللحوم المطبوخة بأنها شهية

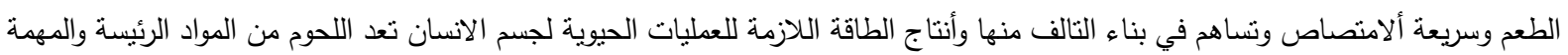

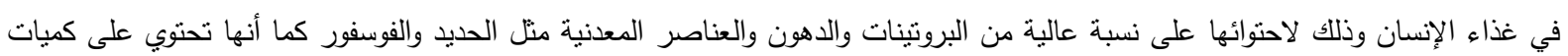

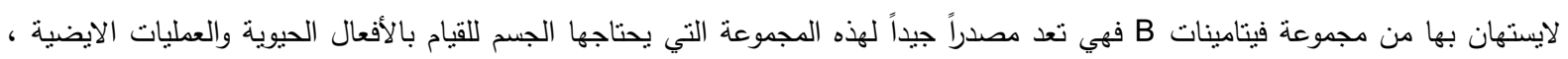

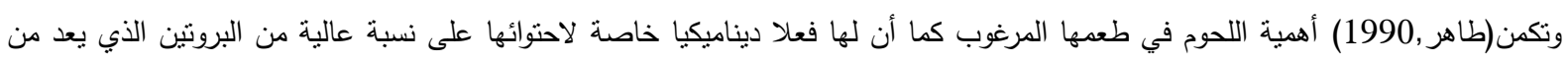

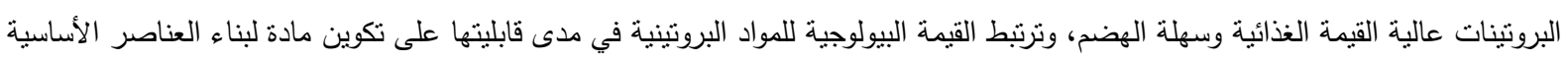

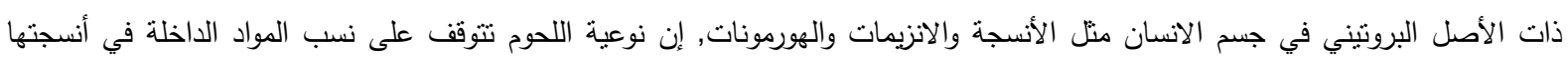

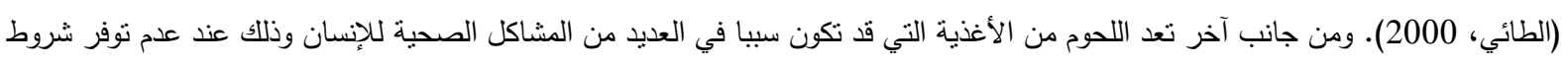

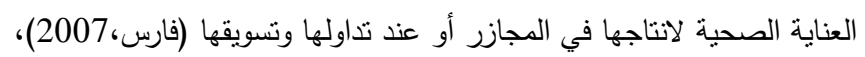

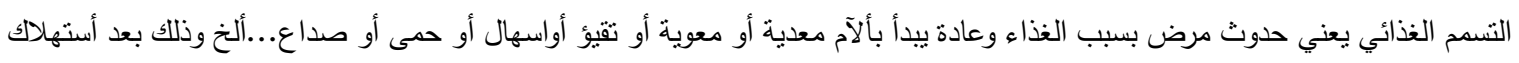

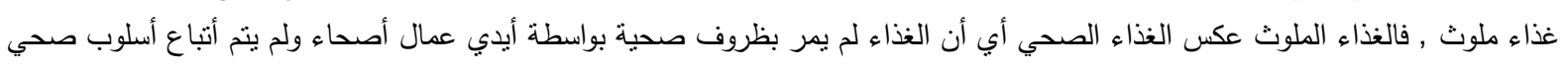

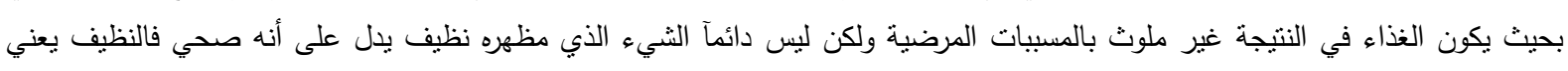

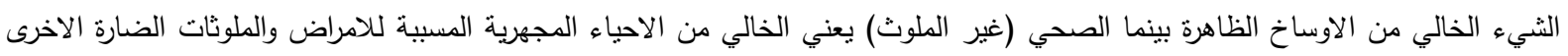

(2005, (2005)

العوينات المستخدمة في الدراسة العمل

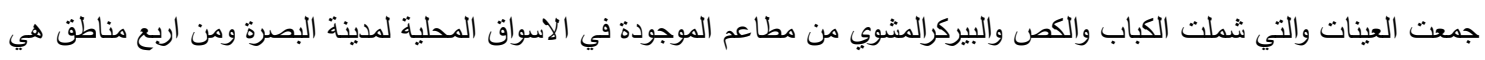

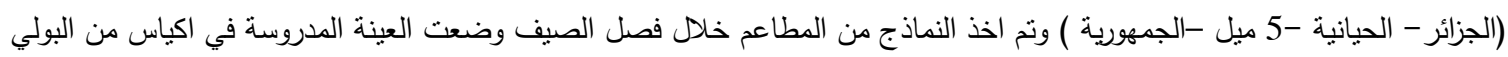

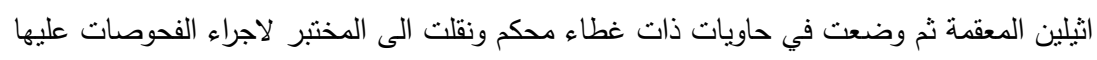

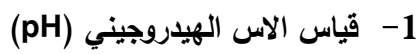

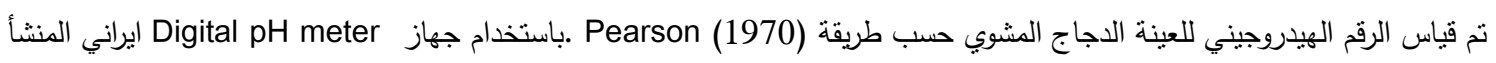

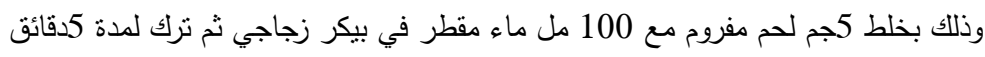


Peroxide value تقدير رقم البيروكسيد

عبارة عن دليل يعكس درجة او مستوى التزنخ في الدهون، نم تقدير رقم البيروكسيد حسب الطريقة الدذكورة من قبل Pearson (1970) باستخدام المعادلة النالية:

Peroxide value $=$

$\mathrm{Na} 2 \mathrm{~s} 2 \mathrm{o} 3 \mathrm{ml} * \mathrm{~N} * 1000$

Wt.of sample(gm

Free fatty acid ق تقدير الاحماض الدهنية الحرة

قدرت الاحماض الدهنية الحرة(FFA) على وفق الطريقة التي اثنار اليه (1970) Pearson باستخدام المعادلة التالية:

Free fatty acid $\%=$

Titration $\mathrm{KoH}(\mathrm{A}-\mathrm{B}) * \mathrm{~N} * 282 * 100$

1000*Wt.of sample(gm

olic acid 282 الوزن الجزئي لحامض الاوليك=الم

الاختبارات البكتيرية

pepton water 1

استخدم لاجراء التخافيف العشرية للمزارع البكتيرية ،حضر باذابة 1غم من الببتون واكمل الحجم الى لتر من الماء المقطر ثم وزع في انابيب

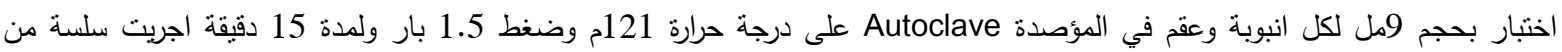

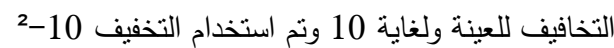

اجريت سلسلة من التخافيف للعينة ولغاية تخفبف 10-2 Culture Mediaة الأوساط الزربية

حضرت الأوساط الزرعية حسب التعليمات التي ورد ذكرها على العبوة من قبل الثركة المصنعة وكما يأتي

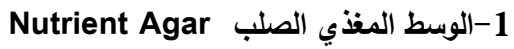

وزن 7 غم من وسط Hutrient agar المجهز من شركة Himedia الهندية وذوب في 250مل من الماء المقطر وسخن لإتمام الإذابة

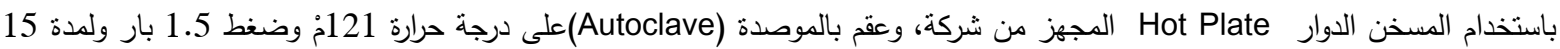
دقيقة وحضن على درجة حرارة 37م ولمدة 48 ساعة.

: MacConkey agar 2

وزن 12.75 غم من وسط MacConkey agar تم تحضير الوسط حسب مواصفات شركة Himedia الهندية وذوب في250مل من

الماء المقطر ثم سخن الوسط لإذابته قليلا بجهاز الاذابة Magnetic stirrerوعق بواسطة الموصدة عند درجة حرارة 121 م وضغط 1.5 بار

لمدة 15 دقيقة

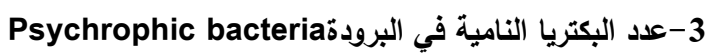

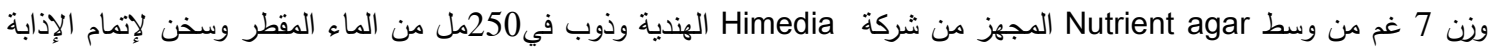

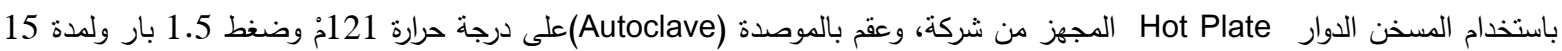
دقيقة والحضن على درجة 7م لمدة 10 ايام

: Staph 110 bـ

تم وزن 27.75 غم من وسط 110 Staph وحضر الوسط حسب مواصفات شركة Himedia الهندية بإضافة الوسط إلى 250مل من الماء المقطر وإذابته بواسطة المسخن الدوار و التعقيم بالموصدة على حرارة121مُ و لمدة 15 دقيقة وضغط 1.5 بار . حسبت اعداد المستعمرات وضربت في مقلوب التخفيف

التحليل الإحصائي:

حلات البيانات باستخدام التصميم العشوائي الكامل Complete Randomized Design ضمن البرنامج الإحصائي الجاهز SPSS Static analysis program (2006) وقورنت النتائج باستخدام اقل فرق معنوي معدل يتوى (0.05) (الراوي وخلف اله، 2000). 
النتائج والمناقشة

رقم البيروكسيد :

يوضح الجدول (1) قياس رقم البيروكسيد للعينات الددروسة التي شملت ( الكباب , الكص , البيركر ) للمناطق الاربع في محافظة البصرة

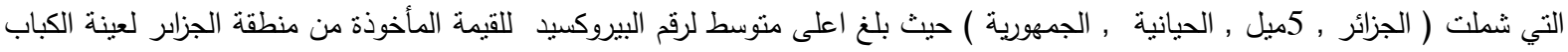

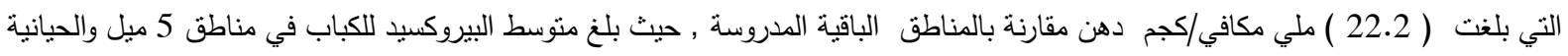

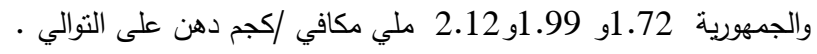

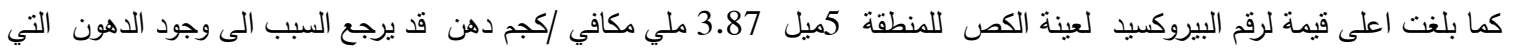

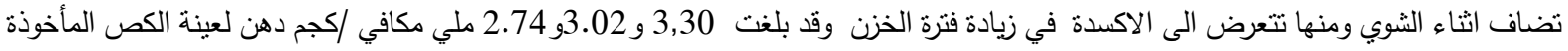

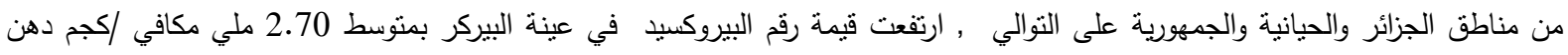

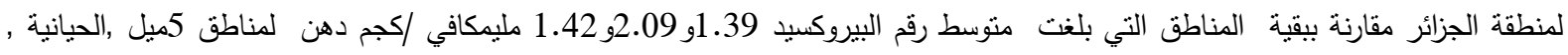
الجمهورية على النوالي

جدول (1) رقم البيروكسيد للعينات المدروسة (ملمكافى/كجم دهن)

\begin{tabular}{|c|c|c|c|c|}
\hline الجمهورية & الحيانية & 5ميل & الجز ائر & المعاملات \\
\hline 2.12 & 1.99 & 1.72 & 2.22 & الكباب \\
\hline 2.74 & 3.02 & 3.87 & 3.30 & الكص \\
\hline 1.42 & 2.09 & 2.39 & 2.70 & البيركر \\
\hline \multicolumn{3}{|c|}{0.198} & & RLSD \\
\hline
\end{tabular}

نسبة الاحماض الدهنية الحرة :

بين جدول (2) قياس قيمة الاحماض الدهنية الحرة للعينات (الكباب , الكص , البيركر ) للمناطق المدروسة والتي شملت ( الجزائر , الحيانية

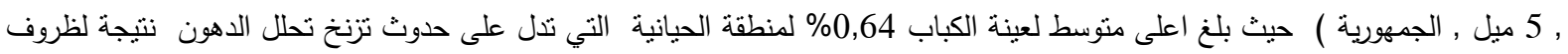
الخزن الغير جيدة وأطالة مدة الخزن كما يلاحظ من الجدول متوسط قيمة الاحماض الدهنية للعينة نفسها لمناطق الجزائر و 5 ميل والجمهورية بلغت

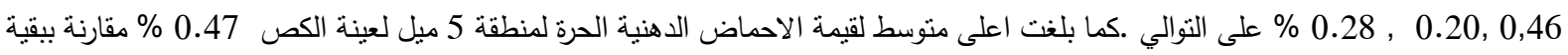
المناطق المدروسة التي بلغت متوسطاتها 2.15 , 0.02, 0,23\% لمناطق الجزائر والحيانية والجمهورية على التوالي , اقل قيمة لرقم الاحماض لماض الدهنية الحرة كان في منطقة الحيانية والتي بلغت 0,28\% لعينة البيركر فيما بلغت متوسطات رقم الاحماض الدهنية الحرة 0,49 , 0,48 ,

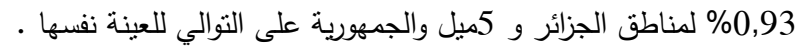

جدول رقم (2) نسبة الاحماض الدهنية الحرة (\%)

\begin{tabular}{|c|c|c|c|c|}
\hline الجمهورية & الحياتية & 5ميل & الجزائر & المعاملات \\
\hline 0.28 & 0.64 & 0.20 & 0.49 & الكباب \\
\hline 0.23 & 0.02 & 0.47 & 2.15 & الكص \\
\hline 0.98 & 0.28 & 0.48 & 0.49 & البيركز \\
\hline \multicolumn{4}{|c|}{0.022} & RLSD \\
\hline
\end{tabular}

رقم الاس الهيدروجين pH

يبين جدول الجدول (3) قيم الرقم الهيدروجيني للعينات (الكباب , الكص , البيركر) للمناطق الدختلفة ( الجزائر , 5ميل , الحيانية , الجمهورية )

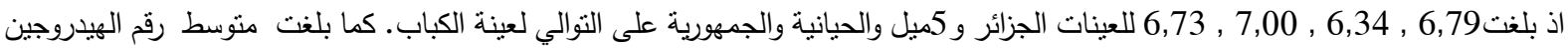

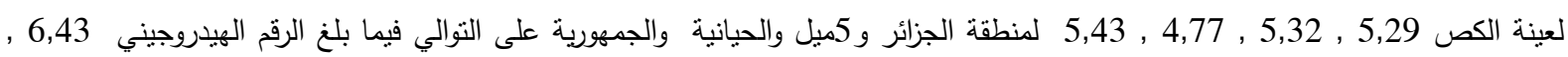

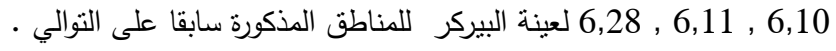

جدول رقم (3) رقم الرقم الهيدروجيني للعينات قيد الدراسة

\begin{tabular}{|c|c|c|c|c|}
\hline الجمهورية & الحيانية & 5ميل & الجز ائر & المعاملات \\
\hline 6.73 & 7.00 & 6.34 & 6.79 & الكباب \\
\hline 5.43 & 4.77 & 5.32 & 5.29 & الكص \\
\hline 6.28 & 6.11 & 6.10 & 6.43 & البيركر \\
\hline \multicolumn{4}{|c|}{6.54} & RLSD \\
\hline
\end{tabular}


التلوث البكتيري:

اعداد بكتريا القولون

بين جدول رقم (4) التلوثاليكروبيولوجى لعينات الكباب والكص والبيركرلمناطق (الجزائر ,5ميل, الحيانية, الجمهورية) أظهرت منطقة الجزائراعلى الجئل

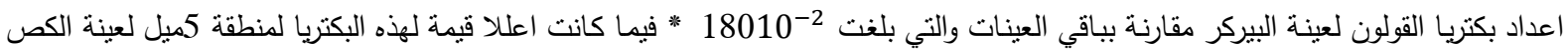

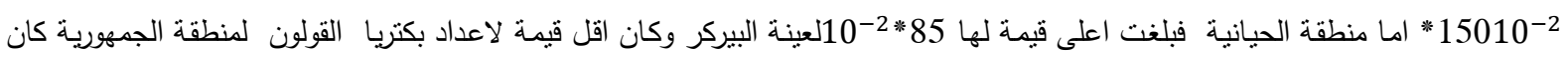

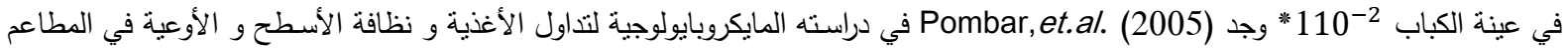

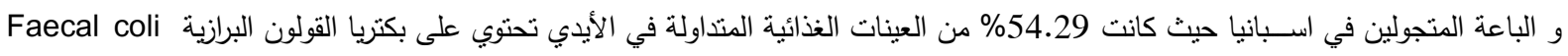
form و هذا يدل على عدم وجود نظافة شخصية كافية و طرق عمل الأغذية غير صحيحة و عدم صحة التداول.

\begin{tabular}{|c|c|c|c|c|}
\hline & & & \multicolumn{2}{|c|}{ جدول رقم (4) الاعداد بكتريا القولون (cuf/جم) } \\
\hline الجمهورية & الحياثية & 5ميل & الجزائر & المعاملات \\
\hline $10 * 10$ & $10 * 80$ & $10 * 85$ & $10 * 35$ & الكباب \\
\hline $10 * 38$ & $10 * 80$ & $10 * 150$ & $10 * 50$ & الكص \\
\hline $10 * 38$ & $10 * 38$ & $10 * 65$ & $10 * 180$ & البيركر \\
\hline \multicolumn{4}{|c|}{21.18} & RLSD \\
\hline
\end{tabular}

اعداد البكتريا المحبة للبرودة :

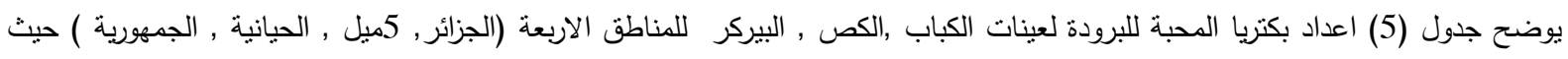

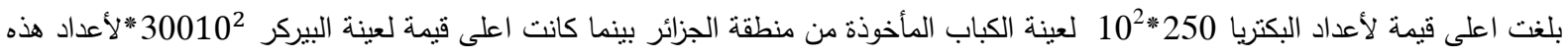
البكتريا المأخوذة من منطقة 5 ميل بينما بلغت اعلى قيمة لهذه البكتريا 35*10 لعينة الكص لمنطقة الحيانية وبلغت 85 "10 لنفس العينة لمنطقة

الجمهورية .

جدول (5) اعداد البكتريا المحبة للبرودة (cuf) جمثر)

\begin{tabular}{|c|c|c|c|c|}
\hline الجمهورية & الحياتية & 5ميل & الجزائر & المعاملات \\
\hline $10 * 35$ & $10 * 33$ & $10 * 90$ & $10 * 250$ & الكباب \\
\hline $10 * 85$ & $10 * 35$ & $10 * 85$ & $10 * 80$ & الكص \\
\hline $10 * 80$ & $10 * 30$ & $10 * 300$ & $10 * 150$ & البيركر \\
\hline
\end{tabular}

أعداد بكتريا المكورات العنقودية :

يوضح جدول (6) اعداد بكتريا المكورات العنقودية لعينات الكباب , الكص , والبيركر للمناطق الاربع ( الجزائر , 5ميل , الحيانية , الجمهورية )

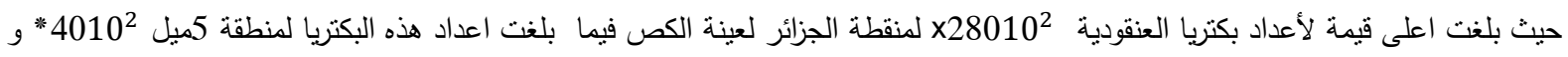

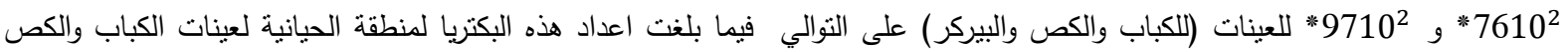

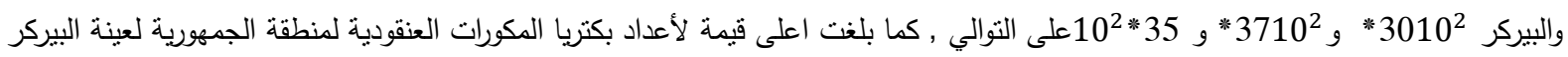

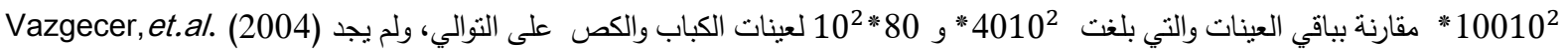
بكتريا Staphylococcus aureus خلال دارسة للنوعية الميكروبيولوجـة لبقايا الطعام و شاورما الدجاج المطبوخة في نركيا.

\begin{tabular}{|c|c|c|c|c|}
\hline & & & \multicolumn{2}{|c|}{ جدول (6) اعداد البكتريا المكورات العنقودية (cuf/جم) } \\
\hline الجمهورية & الحياتية & 5 5 5 & الجزائر & المعاملات \\
\hline $10 * 40$ & $10 * 30$ & $10 * 40$ & $10 * 230$ & الكباب \\
\hline $10 * 80$ & $10 * 37$ & $10 * 76$ & $10 * 280$ & 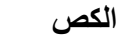 \\
\hline $10 * 100$ & $10 * 35$ & $10 * 97$ & $10 * 150$ & 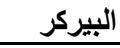 \\
\hline \multicolumn{4}{|c|}{22.18} & RLSD \\
\hline
\end{tabular}

أعداد بكتريا الكلية :

يوضــــح جدول (7) اعداد البكتريا الكلية لعينات الكباب والكص والبيركر لمناطق الجزائر و 5ميل و الحيانية والجمهورية حيث بلغت

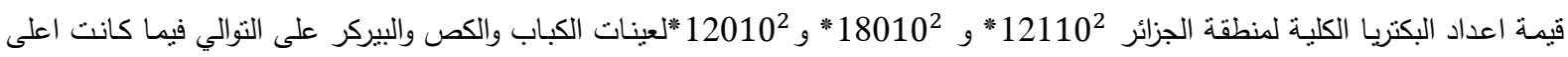

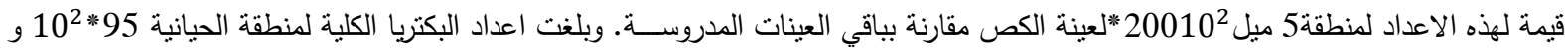


10010² لعينات الكباب والكص وكانت اقل قيمة لها 6910² لعبنة البيركر للمنطقة ذاتها , بينما كانت اعلى قيمة لاعداد البكتريا الكلية لعينة

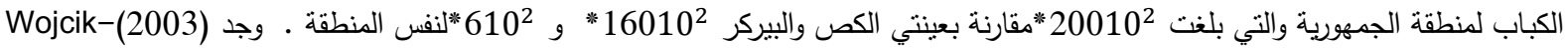
Stopczynska, et. al.

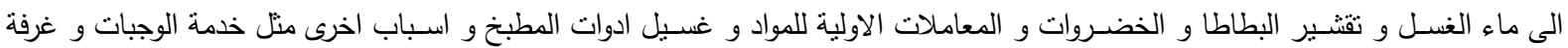
تتاول الطعام.

\begin{tabular}{|c|c|c|c|c|}
\hline & & & \multicolumn{2}{|c|}{ جدول (7) اعداد البكتريا الكلية (cuf/جم) } \\
\hline الجمهورية & الحياتية & 5ميل & الجزائر & المعاملات \\
\hline $10 * 200$ & $10 * 95$ & $10 * 90$ & $10 * 126$ & الكباب \\
\hline $10 * 160$ & $10 * 100$ & $10 * 200$ & $10 * 180$ & 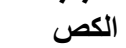 \\
\hline \multirow[t]{3}{*}{$10 * 65$} & $10 * 69$ & $10 * 70$ & 1 & البيركر \\
\hline & & & $10 * 20$ & \\
\hline & & & & \\
\hline
\end{tabular}

محمد،آمال أحمد (2005).أهمية اللحوم كغذاء وأسباب تلوثها.باحث اول بمعهد بحوث صحة الحيوان -اسيوط.(Web sit) فارس، معز الدين عزت (2007). الغذاء والتغذية في الإسلام.من موقع عالم الأغذية / قسم التغذية والأمراض الزاوي، محمد خاثـــع الزاوي وخلف الله، محمد عبد العزيز (2000).تصــــيم وتحليل التجارب الزراعية، دار الكتب للطباعة والنشـــر، جامعة الموصل، العراق. طاهر، محارب عبد الحميد (1990).علم اللحومالطبعة الأولى. وزارة التعليم العالي والبحث العلمي، جامعة البصرة-العراق، صواف 90.

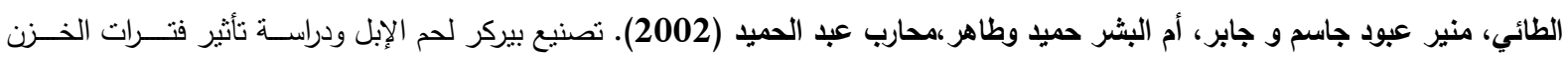

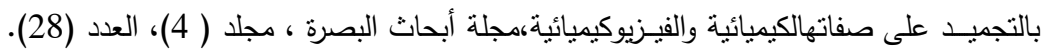

SPSS (2006). Statistical Packages of Social Sciences. Version 15 for windows. SPSS. Inc. USA

Pearson, D.; Egan, H.; Kirk, R. S. and Sawyer, R. (1981). Chemical analysis of food. Longman Scientific and Technical New York, USA.

Vazgecer, B.; Ulu, H. and Oztan, A. (2004).Microbiological and chemical qualities of chicken doner retailed on the Turkish restaurants. J. Food Control 5(4).

Pombar, A.; Gallarado,CS.; Casas,O.; Rego,P. and Rodriguez,LA. (2005). Microbiological evaluation of surfaces, utensils and food handlers in restaurants and canteens. J.Alimentaria. No.364.

Wojcik - Stopczynska, B., Falkowski, J. andAkubowska, J. (2003).Microflora of university canteen air.J.Roczniki Panstwowego Zakladu Higieny.Vol.54.No. 3. 


\title{
Study on chemical changes and microbial contamination on cooked meat presented in some local restaurants in Basrah Governorate
}

\author{
Dr. Ghaidaa Ali Makki \\ Department of Animal Production of Agriculture / University of Basra
}

\begin{abstract}
The present study aimed at studying the bacterial and bacterial contamination of cooked meat in some of the restaurants of Basrah governorate in four regions (Algeria, Hayaniya, Republic and the region of five miles) by measuring the percentage of free fatty acids andperoxide and microbial pollution, which includes total numbers of bacteria, Alklun bacteria, Staphylococcus aureus. The results of the study showed that the highest mean of the peroxid number was the sample of the plank which reached $(3.30,3.87,3.23,2.74)$ In the Algiers region and five miles, Hayaniya and El Gomhouria, respectively. And the highest mean was 2.15 for the sample of Alkz in the region of Algeria, while the lowest average of 0.02 for the area of Hayaniya for the same sample. The preparation of total bacteria and coliform bacteria total $200 * 102$ and $150 * 102$ in the area of five miles where it was related to the results of the limits of the microbial specifications of the year 2000 To the prescribed limit
\end{abstract}

